\title{
Asymmetrical dispersal and putative isolation-by-distance of an intertidal blenniid across the Atlantic-Mediterranean divide
}

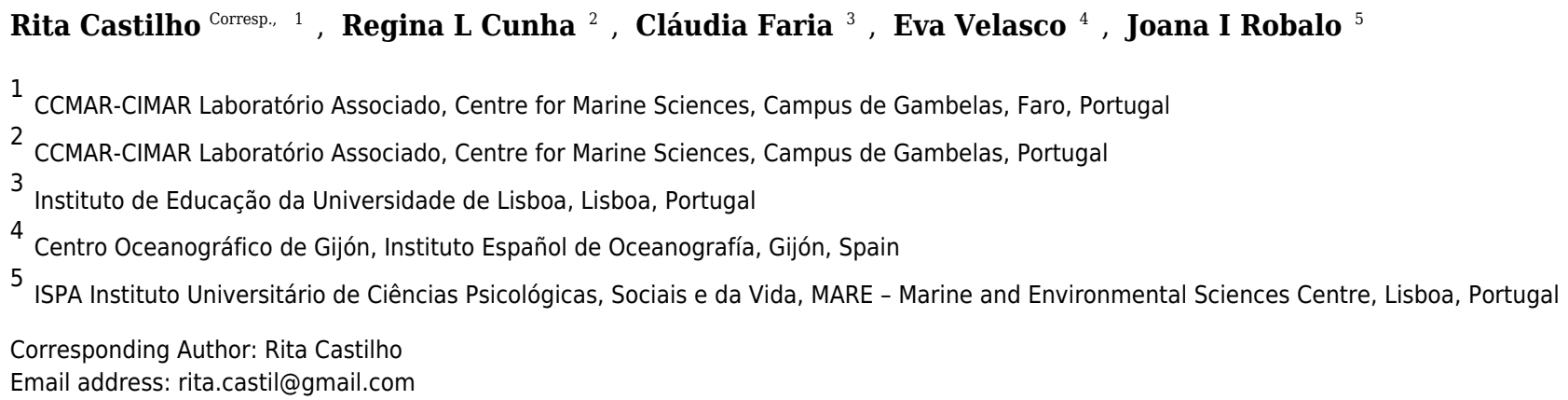

Transition zones are of high evolutionary interest because unique patterns of spatial variation are often retained. Here, we investigated the phylogeography of the peacock blenny, Salaria pavo, a small marine intertidal fish that inhabits rocky habitats of the Mediterranean and the adjacent Atlantic Ocean. We screened 170 individuals using mitochondrial and nuclear sequence data from eight locations. Four models of genetic structure were tested: panmixia, isolation-by-distance, secondary contact and phylogeographic break. Results indicated clear asymmetric migration from the Mediterranean to the Atlantic but only marginally supported the isolation-by-distance model. Additionally, the species displays an imprint of demographic expansion compatible with the last glacial maximum. Although existence of a refugium in the Mediterranean cannot be discarded, the ancestral lineage most likely originated in the Atlantic, where most of the genetic diversity occurs. 


\section{Asymmetrical dispersal and putative isolation-by-distance of an intertidal blenniid across}

2 the Atlantic-Mediterranean divide

3

4 Castilho, R. a , Cunha, R.L. ${ }^{\text {a }}$, Faria, C. ${ }^{\text {c }}$, Velasco, E. ${ }^{\text {d }}$, Robalo, J.I. ${ }^{\text {b }}$

5

6 a Centre for Marine Sciences, CCMAR-CIMAR Laboratório Associado, Campus de Gambelas, 7 Faro, Portugal.

8 b MARE - Marine and Environmental Sciences Centre, ISPA Instituto Universitário de Ciências

9 Psicológicas, Sociais e da Vida, Lisboa, Portugal.

10 c Instituto de Educação da Universidade de Lisboa, Lisboa, Portugal

$11{ }^{\mathrm{d}}$ Centro Oceanográfico de Gijón, Gijón, Spain.

12

13

14 * Corresponding author at: Centre for Marine Sciences, CCMAR-CIMAR Laboratório 15 Associado, Campus de Gambelas, 8005-139 Faro, Portugal.

16 Fax: +351289800069.

17 E-mail address: rcastil@ualg.pt (R. Castilho). 


\section{Abstract}

21 Transition zones are of high evolutionary interest because unique patterns of spatial variation are

22 often retained. Here, we investigated the phylogeography of the peacock blenny, Salaria pavo, a

23 small marine intertidal fish that inhabits rocky habitats of the Mediterranean and the adjacent

24 Atlantic Ocean. We screened 170 individuals using mitochondrial and nuclear sequence data

25 from eight locations. Four models of genetic structure were tested: panmixia, isolation-by-

26 distance, secondary contact and phylogeographic break. Results indicated clear asymmetric

27 migration from the Mediterranean to the Atlantic but only marginally supported the isolation-by-

28 distance model. Additionally, the species displays an imprint of demographic expansion

29 compatible with the last glacial maximum. Although existence of a refugium in the

30 Mediterranean cannot be discarded, the ancestral lineage most likely originated in the Atlantic,

31 where most of the genetic diversity occurs. 


\section{INTRODUCTION}

34 Many terrestrial and marine species have often experienced expanding and contracting range

35 shifts over time (Herborg et al. 2007; Reece et al. 2010; Reuschel et al. 2010). These range shifts

36 are generally promoted by geological or climate events that affect temperature and territorial

37 connectivity between locations. The African and Iberian continental margins formed the

38 Gibraltar arch 5.5 MYA (million years ago) producing a land bridge that interrupted the water

39 flow between the Atlantic and Mediterranean adjacent basins. This event, known as the

40 Messinian Salinity Crisis, turned the Mediterranean hypersaline and dried out large expanses of

41 the basin (Duggen et al. 2003; Hsü et al. 1973; Krijgsman 2002). The Mediterranean Sea was

42 then the ground of a drastic contraction-expansion of distributional range processes in marine

43 organisms inhabiting those waters. The disappearance of the previously existing Tethyan fauna

44 followed by the Mediterranean invasion of Atlantic species through the Strait of Gibraltar, when

45 the land bridge receded, were the main drivers of those distributional processes. Furthermore, the

46 Pleistocene glacial episodes and the consequent fluctuations of the sea level and surface

47 temperature in the Mediterranean and adjacent Atlantic have further shaped the distribution of

48 marine organisms impacting their genetic makeup (Patarnello et al. 2007).

49 The Mediterranean Sea and the contiguous Northeastern Atlantic Ocean were the focus of

50 several phylogeographic studies on marine fish exploring the relationships between populations

51 inhabiting both regions across a well-defined oceanographic break, the Almeria-Oran Front

52 (AOF). The AOF is situated east of the Strait of Gibraltar by the convergent Atlantic and

53 Mediterranean water masses, stretching from Almeria on the Spanish coast to Oran on the

54 Algerian coast. Some species such as Dicentrarchus labrax, Diplodus puntazzo and

55 Coryphoblennius galerita, have shown high genetic divergence between populations inhabiting 
56 both sides of the AOF (Bargelloni et al. 2005; Domingues et al. 2007; Lemaire et al. 2005) while

57 others display evidence of strong genetic flow (e.g., Thalassoma pavo, Chromis chromis and

58 Diplodus sargus - Bargelloni et al. 2005; Costagliola et al. 2004; Domingues et al. 2005). It has

59 proven difficult to assign these differences to a single environmental or biological parameter

60 (e.g. Galarza et al. 2009b).

61 This study is part of an on-going effort to understand the phylogeography of intertidal

62 fish fauna with their areas of distribution centred in the Northeastern Atlantic Ocean and the

63 adjacent Mediterranean Sea (e.g. Almada et al. 2012; Francisco et al. 2009; Robalo et al. 2012).

64 Species with such distribution, different habitat requirements, and diverse larval pelagic

65 durations, provide interesting opportunities to study the evolutionary effects of geographic range

66 shifts and genetic patterns of differentiation. Present in both areas, the peacock blenny, Salaria

67 pavo, occurs mainly around the Western Mediterranean coasts and from the Bay of Biscay south

68 to the Canaries (Zander 1986), being less abundant in the Eastern Mediterranean. This species

69 lives in sheltered rocky habitats and coastal lagoons, in the intertidal, or in the first meters of the

70 subtidal. Contrary to other Blenniidae, the peacock blenny is able to colonize soft substrates

71 (mud and sandy bottoms) and isolated patches of underwater vegetation (Verdiell-Cubedo et al.

72 2006). Salaria pavo displays a high tolerance to salinity (from 2 to $65 \%$ ) and temperature from

$731^{\circ}$ to $30^{\circ} \mathrm{C}$ (Paris \& Quignard 1971; Plaut 1999). Nevertheless, the ecology of the species varies

74 enormously with the availability of spawning grounds (e.g. Almada et al. 1994, and references

75 therein). During the spawning season, males build and defend nests from conspecific males or

76 other intruders and care for the eggs (Gonçalves \& Almada 1997). Eggs of S. pavo are unable to

77 hatch at temperatures below $15^{\circ} \mathrm{C}$ and typically breed at temperatures above $18^{\circ} \mathrm{C}$ (Westernhagen

78 1983). Therefore, at the Last Glacial Maximum (LGM), when temperatures are estimated to have 
79 been between $1.5^{\circ} \mathrm{C}$ in February and $9.5^{\circ} \mathrm{C}$ in August, suitable temperatures for the reproduction

80 of S. pavo were likely absent from the Bay of Biscay, western Galicia and northern Portugal.

81 The goal of this study was to investigate genetic imprints of the peacock blenny, Salaria

82 pavo, using the mitochondrial D-loop and the first intron of the nuclear S7 ribosomal protein

83 gene sequences. More specifically, we assessed the genetic diversity and population structure of

84 this species over its sampled distribution range and evaluated long-term connectivity among

85 populations. We evaluated the following biogeographic hypotheses concerning the current

86 spatial genetic diversity of $S$. pavo: (1) panmixia, whereby there is no discernible geographic or

87 otherwise genetic structure corresponding effectively to a random distribution of haplotypes

88 (Hypothesis 1: Figure 1a); (2) isolation-by-distance (IBD) pattern by which genetic and

89 geographic distances are positively correlated (Wright 1943), and therefore alleles will show a

90 frequency cline pattern between the Atlantic and the Mediterranean (Hypothesis 2: Figure 1b);

91 (3) secondary contact between populations of the two regions, where alleles will transiently show

92 a cline pattern at the contact zone between the two areas (Hypothesis 3: Figure 1c), and (4)

93 genetic phylogeographic break between adjacent regions, wherein a sharp change of allele

94 frequencies is observed between the Atlantic and the Mediterranean (Hypothesis 4: Figure 1d).

MATERIAL AND MethodS

\section{Sampling and generation of molecular data}

98 Samples of S. pavo were collected at 8 localities in the Northwestern Mediterranean and Atlantic

99 coast of the Iberian Peninsula (Table 1; Figure 2). No field permits were required as this species

100 is listed as "least concern conservation status" and it was not captured in protected areas. Fish

101 were caught by scuba diving and small fishnets on rocky beaches and fin clips were stored 
102 individually in $96 \%$ ethanol. Captured fish were held in buckets with aerators, manipulation kept

103 to the minimum time required to collect the smallest fin clip sample possible and quickly placed

104 back in the live-cart prior to release. Fish were observed for general condition before release, and

105 returned to the same pond or location of capture as soon as possible.

106 Total genomic DNA was extracted from fin or muscle samples with the REDExtract-N-Amp kit

107 (Sigma-Aldrich) following the manufacturer's instructions. Voucher specimens are deposited in

108 ISPA (ethanol preserved tissues). We selected two unlinked genes of different genomes to be

109 sequenced: the mitochondrial D-loop and the nuclear S7 ribosomal protein gene (S7, $520 \mathrm{bp}$,

110 including the first intron (Chow \& Hazama 1998). Nuclear and mitochondrial sequences were

111 obtained from the same individuals whenever possible. PCR amplification of mitochondrial D-

112 loop and of the S7, were performed with the following pairs of primers: D-loop - LPro1 and

113 HDL1 (Ostellari et al. 1996) and S7- S7RPEX1F and S7RPEX2R (Chow \& Hazama 1998).

114 PCR amplification reactions were performed in a $20 \mu 1$ total-reaction volume with $10 \mu 1$ of

115 REDExtract-N-ampl PCR reaction mix (Sigma-Aldrich), $0.8 \mu 1$ of each primer $(10 \mu \mathrm{M}), 4.4 \mu 1$

116 of Sigma-water and $4 \mu 1$ of template DNA. An initial denaturation at $94^{\circ} \mathrm{C}$ for 7 min was

117 followed by $35 / 30$ cycles (denaturation at $94^{\circ} \mathrm{C}$ for $30 / 45 \mathrm{~s}$, annealing at $55^{\circ} \mathrm{C}$ for $30 / 45 \mathrm{~s}$, and

118 extension at $72^{\circ} \mathrm{C}$ for 1 minute) and a final extension at $72^{\circ} \mathrm{C}$ for 7 minutes on a BioRad

119 MyCycler thermal cycler (values D-loop/S7, respectively). The same primers were used for the

120 sequencing reaction, and the PCR products were purified and sequenced in STABVIDA

121 (http://www.stabvida.net/). Sequences for each locus were aligned, edited, and trimmed to a

122 common length using the DNA sequence assembly and analysis software GENEIOUS PRO 7.0

123 (Biomatters, LTD, Auckland, NZ). 


\section{Genetic diversity and population differentiation}

126 The gametic phase of multi-locus genotypes of the nuclear S7 intron was determined using the

127 pseudo-Bayesian approach of Excoffier-Laval-Balding (ELB) algorithm (Excoffier et al. 2003),

128 as implemented in ARLEQUIN 3.5 (Excoffier \& Lischer 2010). Gene diversity for both D-loop

129 and S7 fragments, described as haplotype (h) and nucleotide ( $\pi$ ) diversities (Nei 1987), were

130 calculated using ARLEQUIN 3.5 (Excoffier \& Lischer 2010). Observed heterozygosity was also

131 estimated for the S7 fragment. In order to compare haplotype diversity values, the statistics and

132 asymptotic confidence intervals derived by Salicru et al. (1993) were used for both overall

133 diversity comparison and pairwise comparisons between locations. A median-joining network

134 (Bandelt et al. 1999) was constructed in NETWORK v4.5 (luxus-engineering.com) to determine

135 the genealogical relationships among haplotypes and to consider their geographical distributions.

136 POWSIM 4.1(Ryman \& Palm 2006) was used to assess the power of the data and the suitability

137 of sample sizes to detect significant pairwise fixation at different $F_{\mathrm{ST}}$ values. Simulations were

138 carried out for an effective population size of $\mathrm{Ne}=2000$ to yield $F_{\mathrm{ST}}$ values of $0.01,0.02,0.03$,

139 0.04, and 0.05. Although the species may have a larger effective population size, this is not

140 relevant to the analysis because $N$ e only determines the time necessary to reach the target $F_{\mathrm{ST}}$. In

141 all cases, 1000 replicates were run and the power of the analysis was indicated by the proportion

142 of tests that were significant at $\mathrm{P}<0.05$ based on chi-squared tests using the respective allele

143 frequencies at the locus studied.

144 Among the different metrics for population genetic differentiation, we chose to report both

145 fixation indexes (such as FST and $\Phi$ ST) and one genetic differentiation index (Jost $D$ ) because

146 they represent different properties of population partitioning (Bird et al. 2011). Genetic fixation

$147 F_{\mathrm{ST}}$ and $\Phi_{\mathrm{ST}}\left(\right.$ Weir \& Cockerham 1984) were estimated with $10^{3}$ replicates in ARLEQUIN 3.5 
148 (Excoffier \& Lischer 2010). Significance level was corrected with Bonferroni and Jost's $D$

149 differentiation (Jost 2008) (a statistic independent of gene diversity) statistics was estimated with

150 diveRsity package 1.9.5 (Keenan et al. 2013) and significance of differentiation was assessed

151 through the calculation of $95 \%$ confidence limits using a bias corrected method with $10^{4}$

152 bootstraps. Formentera and Galicia, with 2 and one individuals, were not included in diversity

153 and population structure analysis.

154 Mobile species subjected to genetic statistical differentiation tests often fail to display

155 minor amounts of population subdivision even if they exist (Palumbi \& Warner 2003).

156 Therefore, we used SAShA (Spatial Analysis of Shared Alleles) (Kelly et al. 2010) implemented

157 in the MATLAB environment (Mathworks, Inc.) to test hypothesis 1, i.e., determine the extent to

158 which haplotypes are distributed randomly through space. Non-random distributions of

159 haplotypes can be considered departures from panmixia, and occurrence of the same haplotype in

160 different locations can be considered evidence of recent or ongoing gene flow. SAShA generates

161 the observed distribution of geographic distances of each haplotype, as well as a null distribution

162 generated from the same data. SAShA tests for a significant deviation between the arithmetic

163 mean of the observed distance distribution (ODD) and that of the expected distance distribution

164 (EDD). An ODD significantly less than EDD indicates that alleles are under-distributed, and

165 therefore gene flow is restricted. We tested for significance of the difference between ODD and 166 EDD using $10^{4}$ permutations.

167 To test hypothesis 2 , whether the geographical pattern of genetic differentiation is caused

168 by isolation by distance (IBD) we ran Mantel tests (Mantel 1967) for pairwise matrices between

169 geographical distances (kilometres) of the shortest marine path among locations and genetic

170 differentiation (measured as $F_{\mathrm{ST}} /\left(1-F_{\mathrm{ST}}\right), \Phi_{\mathrm{ST}} /\left(1-\Phi_{\mathrm{ST}}\right)$ and $(D /(1-D)$. Mantel tests $(1000$ 
171 randomizations) were performed using mantel.xla 1.2.4 (Briers 2003).

172 To test hypothesis 4, the existence of a phylogeographic barrier dividing the Atlantic

173 from the Mediterranean, an analysis of molecular variance (AMOVA) was used to examine the

174 amount of genetic variability partitioned among that barrier (Excoffier et al. 1992). AMOVA

175 computes the proportion of variation among groups $\left(F_{\mathrm{CT} \text { and }} \Phi_{\mathrm{CT}}\right)$, the proportion of variation

176 among populations within groups $\left(F_{\mathrm{SC} \text { and }} \Phi_{\mathrm{SC}}\right)$ and the proportion of variation within populations

$177\left(F_{\mathrm{ST} \text { and }} \Phi_{\mathrm{ST}}\right)$ (except in the case of S7, where the computation of AMOVA is not possible for $F_{\mathrm{ST}}$,

178 with unknown gametic phase data). A modification of this hypothesis, allowing to consider the

179 existence of other partitions, was also explored with the spatial structure of genetic variation

180 using a Spatial Analysis of Molecular Variance (SAMOVA) (Dupanloup et al. 2002). SAMOVA

181 defines groups of samples that are maximally differentiated from each other. One hundred

182 simulated annealing processes were used for each value of $\mathrm{K}$ (number of groups). The

183 SAMOVA was run from $\mathrm{K}=2$ to the value of $\mathrm{K}$ that maximizes the value of the $F_{C T}$ statistic.

\section{Estimation of gene flow}

186 Salaria pavo adults are not known to undertake active migrations, therefore, instead of referring

187 to migration rates (M), we will refer instead to gene flow $(G) . G$ and population size parameter

$188(\theta)$ were inferred using the maximum likelihood (ML) in MiGRATE-N ver. 4.2.6 (Beerli \&

189 Felsenstein 1999) among Atlantic and Mediterranean locations in order to determine the degree

190 and direction of migrants across the Atlantic-Mediterranean region. Analyses were first run with

191 a full migration matrix in which gene flow was unrestricted between Atlantic and Mediterranean

192 (asymmetric migration, 4 parameters). To explicitly test other models (including panmixia; 
193 immigration into Mediterranean; immigration into Atlantic) we built custom matrices

194 representing gene flow conditions. All $G$ and $\theta$ were calculated using F $_{S T}$ estimates and UPGMA

195 as starting points, and taking into account the model of evolution. A Markov Chain Monte Carlo

196 was run for three short chains of $10^{4}$ trees and two long chains of $10^{5}$ trees with a burn-in of $10^{3}$

197 trees and a static heating scheme with start temperatures of 1.00, 1.50, 3.00 and 6.00. Finally,

198 likelihood scores for all migration models were obtained by a thermodynamic integration with

199 Bezier approximation (Gelman \& Meng 1998), as implemented in the software. Direct

200 comparison of models was assessed by manually transforming these likelihood scores into Bayes

201 Factors (Kass \& Raftery 1995), which was performed using the method described in Beerli and

202 Palczewski (Beerli \& Palczewski 2010). MigRATE-N was run on CCMAR (Centre for Marine

203 Sciences) Computational Cluster Facility (http://gyra.ualg.pt/) and on the R2C2 research group

204 cluster facility, provided by the IT department of the University of Algarve.

205

206 Population demography

207 Past population demography of $S$. pavo was inferred with the Atlantic D-loop data using the

208 coalescent Bayesian skyline plot (BSP) model as implemented in BEAST v. 2.3.1 (Ho et al.

209 2005) employing the Bayesian MCMC coalescent method, a strict clock and the $\mathrm{HKY}+\mathrm{I}+\mathrm{G}$

210 model of substitution obtained in Modeltest v. 3.7 (Posada \& Crandall 1998), using the Akaike

211 information criterion (AIC) (Akaike 1974). Results were visualized in TRACER v. 1.5 (Rambaut

212 \& Drummond 2007). The Bayesian distribution was generated using results from two

213 independent run of 100 million MCMC steps obtaining effective samples sizes (ESS) of

214 parameter estimates of over 200 . We used a mutation rate of $3.6 \%$ per million years calculated in

215 previous studies where geological events were available to calibrate the rate of D-loop 
216 divergence in marine fish (Donaldson \& Wilson 1999) and in the absence of a clock calibration

217 for the D-loop of $S$. pavo we address the rate uncertainty by assuming two additional higher

218 within-lineage mutation rates of $5 \%$ and $10 \%$ per million years.

219

220

221

222

223

224

225

226

227

228

229

230

231

232

233

234

235

236

237 d'Água and Barcelona.

A total of 131 D-loop sequences (GenBank accession numbers: HQ857214-HQ857383) were obtained. The D-loop data set after alignment consisted of a total of $300 \mathrm{bp}$ comprising 52 polymorphic sites (17\%) and $10(3 \%)$ parsimony informative sites. Overall, mtDNA diversity was high, with 49 haplotypes recovered. A large proportion of haplotypes (57\%) were singletons, i.e., represented by a single individual. Forty haplotypes $(82 \%)$ were private, i.e. occurred in only one location. On total, $92 \%$ of haplotypes had a frequency lower than five individuals. The most frequent haplotype in the Atlantic was shared by 25 individuals, followed by two haplotypes shared by 13 individuals, one present only in the Mediterranean and the other in both Mediterranean and Atlantic (Fig. 2). Regarding the 11 haplotypes shared among locations (Fig. 2), six include individuals from both Atlantic and Mediterranean sampling sites. The presence of many low-frequency closely related haplotypes returns high haplotype diversity $(0.952 \pm 0.0078)$ and an average nucleotide diversity $(3.63 \% \pm 1.84 \%)$ of the overall sample, as well as in each locality (Table 1). Haplotype diversity values were not significantly different between locations, according to the test developed by Salicru et al. (1993) $(\chi 2=7.15, p>0.05)$, except Sado which displayed a significantly lower haplotype diversity when compared to Cadiz, Ria Formosa, Olhos 

elements. No evident geographic structure could be depicted from this network, i.e., no discernable association between certain haplotypes and locations can be observed. Although the most frequent haplotype was only present in Portugal and Cadiz, the remaining haplotypes from these localities group together with haplotypes from the Mediterranean. The difference between the overall observed distance distribution (ODD) and the expected distance distribution (EDD) of 244 shared alleles rejected the assumption of panmixia (hypothesis 1 ) for the D-loop dataset (ODD = $237 \mathrm{~km}, \mathrm{EDD}=516 \mathrm{~km}, p<0.00001)\left(\right.$ Fig. 4). POWSIM indicated that a $F_{\mathrm{ST}}$ of $\geq 0.0248($ time in generations $=150)$ could be detected with $\geq 95 \%$ confidence $(95.5 \%$ Fisher's exact test, $96.2 \%$ chi-square). When $F_{\mathrm{ST}}$ was set to zero (simulating no divergence among samples), the proportion of $\alpha$ error of type I (rejecting null hypothesis when true) was lower than $5 \%$. Mediterranean, between the Mediterranean and Atlantic and intra-Atlantic) showed a tendency for higher Atlantic-Mediterranean values (Fig. 5A). Pairwise location genetic differentiation 252 revealed no association between the levels of differentiation and the three geographical groups 253 considered (Fig. 5B). There is no clear indication of a genetic break (hypothesis 4) between the 254 Mediterranean and Atlantic Ocean as pairwise differentiation values were all within the same range. Isolation-by-distance model (hypothesis 2) support was equivocal, the null hypothesis of no correlation between geographic and genetic distances was not rejected using $F_{\mathrm{ST}}(\mathrm{r}=-0.075$;

257 significance of $z=0.3960)$ and $\Phi_{\mathrm{ST}}(r=0.343$; significance of $\mathrm{z}=0.1140)$ but was rejected using 258 $D(\mathrm{r}=0.623$; significance of $\mathrm{z}=0.001)$. No haplotype frequency cline (hypothesis 3$)$ could be 259 detected as there were only three haplotypes shared between more than 2 locations. 
260 There was no support for hypothesis 4 (in Appendix S1_AMOVA_Dloop) indicating non-

261 significant results when we use a strict Mediterranean-Atlantic partition $\left(F_{\mathrm{CT}}=-0.009, p\right.$-value $=$

262 0.733; and $\Phi_{\mathrm{CT}}=0.071, p$-value $=0.072$ ), or when we use Barcelona as the sole location

263 representative of the Mediterranean Sea $\left(F_{\mathrm{CT}}=-0.027, p\right.$-value $=0.822$; and $\Phi_{\mathrm{CT}}=0.209, p$ -

264 value $=0.159$ ). AMOVA results (in Appendix S1_AMOVA). The SAMOVA results showed that

$265 F_{\mathrm{CT}}$ statistic does not increase as the number of groups increased (in Appendix S1_SAMOVA).

266 The location arrangements that maximized $F_{\mathrm{CT}}$ were: 2-group (BA)(CG-CA-RF-OA-SA); 3 -

267 group (BA)(CG-CA-RF-OA)(SA); 4-group (BA)(CG)(CA-RF-OA)(SA) and finally 5-group

268 (BA)(CG)(CA)(RF-OA)(SA). None of the $F_{\mathrm{CT}}$ values were significant, however, the 4-groups

269 arrangement was marginally non-significant $(p$-value $=0.0583)$.

270 Migrate-N was run to determine the level and direction of gene flow across the Almeria-

271 Oran oceanographic boundary. The estimated log Bayes factors based on the Bezier

272 approximation score indicated that the most probable model is the one that contemplates

273 asymmetric migration between the Atlantic and the Mediterranean (Table 2). The number of

274 migrants from the Mediterranean to the Atlantic was ca. three times the number of migrants in 275 the inverse direction.

276 The Bayesian skyline plot indicated that the Western Mediterranean and Atlantic locations

277 of $S$. pavo have experienced a long period of demographic stability in the past, followed by a

278 mild decrease of population size and a quick expansion (Fig. 6). The plot indicates a pronounced

279 ca.100-fold demographic expansion event. The timeframe of this expansion event is totally

280 dependent on the mutation rates used. Rates of 3.6, 5 and 10\%/MY result in expansion dates of

28156,000 years, 40,000 years and 20,000 years ago respectively.

282 


\section{First S7 intron}

284 A total of 136 S7 first intron sequences (GenBank accession numbers: JF834709-JF834885)

285 were obtained. The S7 nuclear region data set after alignment consisted of 519 characters, with

286 seven polymorphic sites, among which five with ambiguities. Using the ELB algorithm, we

287 defined 12 closely related alleles, with four abundant and almost ubiquitous alleles, and the

288 remainder represented by only one or two individuals. Overall gene and nucleotide diversities

289 were low, $0.69 \pm 0.02$ and $0.18 \% \pm 0.14 \%$, respectively. The haplotype network (Figure 2)

290 evidences a lack of geographical structure detected by S7, corroborated by both the AMOVA

291 analysis, which returned the proportion of variation among Mediterranean and Atlantic non-

292 significant $\left(\Phi_{\mathrm{CT}}=-0007, p\right.$-value $\left.=0.618\right)($ Appendix S1). Also pairwise comparisons between

293 locations, which returns three significant values, always involving Ria Formosa location (Ria

294 Formosa - Cabo de Gata; Ria Formosa - Cadiz; Ria Formosa - Sado) (Appendix S1) and non-

295 significant values for the isolation-by-distance Mantel test (Appendix S1). The difference

296 between the overall observed distance distribution (ODD) and the expected distance distribution

297 (EDD) of shared alleles does not reject the assumption of panmixia for the S7 dataset (ODD =

$298522 \mathrm{~km}, \mathrm{EDD}=509 \mathrm{~km}, p>0.62)$.

299

300 DiscuSSION

301 In this study, we evaluated four plausible phylogeographic scenarios to explain putative genetic

302 differentiation between Mediterranean and Atlantic samples of Salaria pavo (Figure 1). The

303 nuclear marker, with only 12 haplotypes displayed comparatively low genetic diversity, probably

304 due to low mutation rates (Harpending 1994). From the haplotype network one can also clearly

305 infer that there is no geographical structure. We will therefore discuss in more detail the mtDNA 
306 results. Pure models of panmixia, secondary contact, and presence of a phylogeographic break do

307 not seem to explain the results obtained, while isolation-by-distance with asymmetric migration

308 between the Atlantic and Mediterranean is a more plausible explanation. Before dissecting these

309 results, it is appropriate to address two main caveats regarding this work. Firstly, we are

310 contrasting our results with well-defined hypotheses that constitute extremes of often less clear

311 biological realities. Isolation-by-distance and clines are not mutually exclusive genetic patterns,

312 as illustrated by ring species (Irwin et al. 2001), in which a series of intermediate subpopulations

313 display a contact zone and are often connected by a cline at the closure of the ring (Bensch et al.

314 2009). Although the isolation-by-distance tests were only significant using the Jost's $D$, this is a

315 sound metric to evaluate the genetic differentiation irrespective of haplotype diversity and

316 genetic distance between populations (Bird et al. 2011). Our results seem to reject panmixia,

317 secondary contact and phylogeographic break models, and there is no evidence suggesting that a

318 combination of these would be a better fit. Secondly, the nuclear data display limited variability

319 and no phylogeographic patterns could be identified, showing that S7 was not a good candidate

320 gene for this particular species, although it has been successfully used in other marine fish (Ahti

321 et al. 2016). Thirdly, the migration estimation must be taken with caution, because not all

322 assumptions behind the method used were met (i.e. Migrate-N assumes a constant effective

323 population size).

\section{Model evaluation}

326 Panmixia (hypothesis 1) was concomitantly rejected by the haplotype network (Figure 3), the

327 spatial analysis of shared alleles (Figure 4) and the Migrate-n results (Table 2). Moreover, the

328 presence of private haplotypes detected in both Mediterranean and Atlantic locations and the fact 
329 that some of these were found multiple times on a single location suggests some limitations to

330 gene flow (Hartl \& Clark 1997). Results regarding the classical isolation-by-distance regression

331 model (hypothesis 2) were somewhat equivocal: rejection of the model based on $F_{\mathrm{ST}}$ and $\Phi_{\mathrm{ST}}$,

332 and non-rejection based on Jost's $D$. Because Jost's $D$ is independent from gene diversity, and it

333 was shown to perform well in evaluating genetic differentiation regardless of haplotype diversity

334 and genetic distance between populations (Bird et al. 2011), we do not entirely reject the

335 isolation-by-distance model. We found no support for hypothesis 3 (secondary contact) as most

336 haplotypes are singletons or are shared between two locations, and no haplotype frequency cline

337 could be detected. There is no evidence for a specific association between haplotype presence

338 and locations, such as detected under a phylogeographic barrier (hypothesis 4), with all AMOVA

339 among group $F_{\mathrm{CT}}$ values returning non-significant. A modification of this hypothesis in which

340 several groups are considered, was tested by implementing SAMOVA. The 4-group

341 (BA)(CG)(CA-RF-OA)(SA) arrangement is the one that maximizes $F_{\mathrm{CT}}$, when compared to all

342 other possible groups (two, three and five-group arrangement), and it is also the one that that

343 makes sense from the geographical and isolation-by-distance viewpoint. Barcelona, well in the

344 Mediterranean constitutes a separate group; Cabo de Gata, is on the frontier of the Alboran Sea,

345 is also separate; Cadiz, Ria Formosa and Olhão, are all situated in the Atlantic region adjacent to

346 the Strait of Gibraltar, forms another group; and finally, Sado a clearly Northeastern Atlantic

347 location.

349 The Atlantic-Mediterranean continuum and ancestral areas of refugia

350 Some fish species display a strong genetic discontinuity between each side of the Almeria-Oran

351 oceanographic front, but this pattern is species-dependent. In the same family (e.g. Sparidae 
352 Bargelloni et al. 2003; Galarza et al. 2009a) and even within the same genus (e.g. Diplodus: D.

353 puntazzo and $D$. sargus, Bargelloni et al. 2005), there are species with strong gene flow across

354 the boundary, while others have restricted gene flow. Salaria pavo displays no significant

355 differentiation across the Atlanto-Mediterranean boundary and this permeability contrasts with

356 the strong across-boundary differentiation displayed by another intertidal blenniid

357 Coryphoblennius galerita (Francisco et al. 2014). The strong thermohaline density gradient

358 nature of the Almeria-Oran oceanographic front, is apparently not sufficient to restrict the

359 mobility of S. pavo across the boundary. On the other hand, the paleotemperatures estimated for

360 the summer spawning season during the last glacial maximum (LGM) were at most $13^{\circ} \mathrm{C}$ in the

361 Iberian Atlantic and most of west Mediterranean (CLIMAP 1981) which are not compatible with

362 the high thermal preferences of S. pavo. This species' embryos kept in laboratory arrest their

363 development at temperatures of $15^{\circ} \mathrm{C}$ or lower (Westernhagen 1983). Considering these

364 conditions, S. pavo was at the LGM most likely extirpated from its northern limit, the Bay of

365 Biscay, as well as from North and Central Portugal. These locations represent postglacial

366 colonizations derived from potential refugia located in the Mediterranean or further south in the

367 Atlantic. The most northern location with a representative number of individuals (Sado) displays

368 a significantly lower haplotype diversity values than those found in other Atlantic (Cadiz, Ria

369 Formosa and Olhos d'Água) and Mediterranean locations (Barcelona), which is concordant with 370 a postglacial colonization event.

371 The most probable refugium can be inferred by coalescent theory in which ancestral

372 mitochondrial haplotypes are likely to have given rise to more derived ones because mutation has

373 occurred over a longer period of time (Posada \& Crandall 2001). As a consequence, older

374 haplotypes tend to have more connections in a network. Although homoplasy and high mutation 
375 rates can bias this pattern, highly connected haplotypes tend to be closely related to ancestral

376 haplotypes (Posada \& Crandall 2001). Thus, the presence of highly connected haplotypes in the

377 Atlantic could indicate this region as the likely major source of S. pavo post-glacial

378 recolonization (Fig. 2). However, if gene flow persisted between Atlantic and west

379 Mediterranean during the LGM, both areas may have operated as a vast refugium for the species.

380 The hypothesis of a single refugium located inside the Mediterranean seems the least probable,

381 but no definitive conclusions can be drawn.

382 The asymmetric gene flow detected in the peacock blenny is counterintuitive to expectations

383 based on the prevalent out-of-Mediterranean surface currents (Naranjo et al. 2015). We posit that

384 the unidirectional dispersal direction, also observed in other species (Alberto et al. 2008; Xavier

385 et al. 2011) is disproportionally affected by sporadic storms that alter near-shore counter-currents

386 (Relvas \& Barton, 2002) and surface wind patterns rather than yearly or decadal averages of

387 oceanographic conditions. Because the species lives and spawns in sheltered rocky habitats and

388 coastal lagoons in the intertidal, or in the first meters of the subtidal, it is likely that costal water

389 circulation patterns will affect more decisively its dispersion than the Atlantic-Mediterranean Sea

390 general circulation model.

391

392 Other factors contributing to the present pattern

393 Salaria pavo differs from other blennids by living preferentially in sheltered rocky habitats,

394 estuaries and lagoons (Zander 1986). Although the pelagic larval duration is of ca. 18 days at a

395 temperature of $21^{\circ} \mathrm{C}$ (Westernhagen 1983), it seems likely that larvae from such sheltered

396 habitats can be subject to more efficient retention than those of other blennids of more exposed

397 shores. Salaria pavo's differentiation pattern is consistent with a combination of considerable 
398 individual retention with sporadic episodes of range dispersal, which would reconcile the

399 observation of high $D, F_{\mathrm{ST}}$ and $\theta_{\mathrm{ST}}$ values between locations separated by hundreds of kilometers

400 with substantial sharing of haplotypes between other locations. However, one cannot discard the

401 possibility of phylopatry or a recent limitation to gene-flow acting on a past panmitic population.

402 Previously published work hypothesized that the reduced genetic variation detected in $S$.

403 pavo could have been the result of a severe bottleneck event (Almada et al. 2009). However, we

404 have found a high number of widely distributed haplotypes, coupled with generally significant

$405 F_{\mathrm{ST}}, \Phi_{\mathrm{ST}}$ and $D$ jost values for D-loop and an expansion signature, findings that do not support the

406 hypothesis of a severe bottleneck. Results of the Bayesian skyline plot (BSP) of the S. pavo

407 lineage A (Fig. 6) suggested a recent and rapid 100-fold increase in population size, preceded by

408 a minor decrease that followed an extended period of stability. The lack of a species-specific

409 clock and associated error requires cautious interpretation of age estimates, but the assumed rates

410 of $3.6 \%, 5 \%$ and $10 \% / \mathrm{MY}$ place the expansion unequivocally during the Pleistocene.

412

In summary, we propose that the genetic pattern of S. pavo in the Atlanto-Mediterranean

413 region is better explained by a combination of some degree of isolation-by-distance and

414 asymmetric migration. The ancestral lineage most probably originated in the Atlantic, where

415 most of the genetic diversity is present. Both dispersal potential and physical factors such as

416 local oceanographic conditions are playing a major role in shaping the genetic structure of this

417 species.

418

419 Acknowledgements

420 We are grateful to Sónia Chenu for her help with the lab work and to Marta Pascual and Ferran 
421 Palero, from the University of Barcelona, for their assistance in implementing the Salicrú test of

422 haplotype diversity. Collection of specimens complied with the current laws of each country. We

423

424

425

426

427

428

429

430

431

432

433

434

435

436

437

438

439

440

441

442

443

444

445

446

447

448

449

450

451

452

453

454

455

456

457

458 would like to acknowledge the contribution of the referees for this final version. We dedicate this

paper to the loving memory of Prof. Vítor Almada who died during the course of this work.

Ahti PA, Coleman RR, DiBattista JD, Berumen ML, Rocha LA, and Bowen BW. 2016. Phylogeography of Indo-Pacific reef fishes: sister wrasses Coris gaimard and C. cuvieri in the Red Sea, Indian Ocean and Pacific Ocean. Journal of Biogeography 43:1103-1115 DOI $10.1111 /$ jbi.12712

Akaike H. 1974. A new look at the statistical model identifications. IEEE Transactions on automatic control 19:716-723

Alberto F, Massa S, Manent P, Diaz-Almela E, Arnaud-Haond S, Duarte CM, and Serrao EA. 2008. Genetic differentiation and secondary contact zone in the seagrass Cymodocea nodosa across the Mediterranean-Atlantic transition region. Journal of Biogeography 35:1279-1294

Almada VC, Almada F, Francisco SM, Castilho R, and Robalo JI. 2012. Unexpected high genetic diversity at the extreme Northern geographic limit of Taurulus bubalis (Euphrasen, 1786). PLoS One 7:e44404

Almada VC, Gonçalves EJ, Santos AJ, and Baptista MC. 1994. Breeding ecology and nest aggregations in a population of Salaria pavo (Pisces: Blenniidae) in an area where nest sites are very scarce. Journal of Fish Biology 45:819-830

Almada VC, Robalo J, Levy A, Freyhoff J, Bernardi G, and Doadrio I. 2009. Phylogenetic analysis of Peri-Mediterranean blennies of the genus Salaria: Molecular insights on the colonization of freshwaters. Molecular Phylogenetics and Evolution 52:424-431 DOI 10.1016/j.ympev.2009.03.029

Bandelt H-J, Forster P, and Röhl A. 1999. Median-joining networks for inferring intraspecific phylogenies. Molecular Biology and Evolution 16:37-48

Bargelloni L, Alarcon JA, Alvarez MC, Penzo E, Magoulas A, Palma J, and Patarnello T. 2005. The Atlantic-Mediterranean transition: Discordant genetic patterns in two seabream species, Diplodus puntazzo (Cetti) and Diplodus sargus (L.). Molecular Phylogenetics and Evolution 36:523-535 DOI 10.1016/j.ympev.2005.04.017

Bargelloni L, Alarcon JA, Alvarez MC, Penzo E, Magoulas A, Reis C, and Patarnello T. 2003. Discord in the family Sparidae (Teleostei): divergent phylogeographical patterns across the Atlantic-Mediterranean divide. Journal of Evolutionary Biology 16:1149-1158 DOI 10.1046/j.1420-9101.2003.00620.x 
459

460

461

462

463

464

465

466

467

468

469

470

471

472

473

474

475

476

477

478

479

480

481

482

483

484

485

486

487

488

489

490

491

492

493

494

495

496

497

498

499

500

501

502

503

Beerli P, and Felsenstein J. 1999. Maximum likelihood estimation of migration rates and effective population numbers in two populations using a coalescent approach. Genetics 152:763-773

Beerli P, and Palczewski M. 2010. Unified framework to evaluate panmixia and migration direction among multiple sampling locations. Genetics 185:313-326 DOI 10.1534/genetics.109.112532

Bensch S, Grahn M, Müller N, Gay L, and Åkesson S. 2009. Genetic, morphological, and feather isotope variation of migratory willow warblers show gradual divergence in a ring. Molecular Ecology 18:3087-3096

Bird CE, Karl SA, and Toonen R. 2011. Detecting and measuring genetic differentiation. In: Koenemann S, Held C, and Schubart C, eds. Crustacean Issues: Phylogeography and Population Genetics in Crustacea, 31-55.

Briers R. 2003. Mantel XLA. VBA add-in for Microsoft EXCEL. Available: http://www.lifesciences.napier.ac.uk/staff/rob/sotfware/index.html.

Chow S, and Hazama K. 1998. Universal PCR primers for S7 ribosomal protein gene introns in fish. Molecular Ecology 7:1255-1256

CLIMAP. 1981. Seasonal reconstruction of the Earth's surface at the last glacial maximum. Geological Society of America Map Chart Series. Boulder, CO.: Geological Society of America

Costagliola D, Robertson DR, Guidetti P, Stefanni S, Wirtz P, Heiser J, and Bernardi G. 2004. Evolution of coral reef fish Thalassoma spp. (Labridae). 2. Evolution of the eastern Atlantic species. Marine Biology 144:377-383 DOI 10.1007/s00227-003-1200-y

Domingues V, Bucciarelli G, Almada VC, and Bernardi G. 2005. Historical colonization and demography of the Mediterranean damselfish, Chromis chromis. Molecular Ecology 14:4051-4063 DOI 10.1111/j.1365-294X.2005.02723.x

Domingues VS, Faria C, Stefanni S, Santos R, Brito A, and Almada VC. 2007. Genetic divergence in the Atlantic-Mediterranean Montagu's blenny, Coryphoblennius galerita (Linnaeus 1758) revealed by molecular and morphological characters. Molecular Ecology 16:3592-3605 DOI 10.1111/j.1365-294X.2007.03405.x

Donaldson KA, and Wilson RR. 1999. Amphi-Panamic geminates of Snook (Percoidei: Centropomidae) provide a calibration of the divergence rate in the mitochondrial DNA control region of fishes. Molecular Phylogenetics and Evolution 13:208-213 DOI 10.1006/mpev.1999.0625

Duggen S, Hoernle K, van den Bogaard P, Rupke L, and Morgan JP. 2003. Deep roots of the Messinian salinity crisis. Nature 422:602-606 DOI 10.1038/nature01553

Dupanloup I, Schneider S, and Excoffier L. 2002. A simulated annealing approach to define the genetic structure of populations. Molecular Ecology 11:2571-2581

Excoffier L, Laval G, and Balding D. 2003. Gametic phase estimation over large genomic regions using an adaptive window approach. Human Genomics 1:7-19

Excoffier L, and Lischer HEL. 2010. Arlequin suite ver 3.5: a new series of programs to perform population genetics analyses under Linux and Windows. Molecular Ecology Resources 10:564-567 DOI 10.1111/j.1755-0998.2010.02847.x

Excoffier L, Smouse PE, and Quattro JM. 1992. Analysis of molecular variance inferred from metric distances among DNA haplotypes - application to human mitochondrial-DNA restriction data. Genetics 131:479-491 
504 Francisco S, Castilho R, Soares M, Congiu L, Brito A, Vieira M, and Almada VC. 2009.

505

506

507

508

509

510

511

512

513

514

515

516

517

518

519

520

521

522

523

524

525

526

527

528

529

530

531

532

533

534

535

536

537

538

539

540

541

542

543

544

545

546

547

548
Phylogeography and demographic history of Atherina presbyter (Pisces: Atherinidae) in the North-eastern Atlantic based on mitochondrial DNA. Marine Biology 156:1421-1432

Francisco SM, Almada VC, Faria C, Velasco EM, and Robalo JI. 2014. Phylogeographic pattern and glacial refugia of a rocky shore species with limited dispersal capability: the case of Montagu's blenny (Coryphoblennius galerita, Blenniidae). Marine Biology 161:25092520

Galarza JA, Carreras-Carbonell J, Macpherson E, Pascual M, Roques S, Turner GF, and Rico C. 2009a. The influence of oceanographic fronts and early-life-history traits on connectivity among littoral fish species. Proceedings of the National Academy of Sciences of the United States of America of the United States of America 106:1473-1478 DOI 10.1073/pnas.0806804106

Galarza JA, Turner GF, Macpherson E, and Rico C. 2009b. Patterns of genetic differentiation between two co-occurring demersal species: the red mullet (Mullus barbatus) and the striped red mullet (Mullus surmuletus). Canadian Journal of Fisheries and Aquatic Sciences 66:1478-1490 DOI 10.1139/F09-098

Gelman A, and Meng X. 1998. Simulating normalizing constants: from importance sampling to bridge sampling to path sampling. Statistical science 13:163-185

Gonçalves E, and Almada VC. 1997. Sex differences in resource utilization by the peacock blenny. Journal of Fish Biology 51:624-633 DOI 10.1111/j.1095-8649.1997.tb01517.x

Harpending H. 1994. Signature of ancient population growth in a low-resolution mitochondrial DNA mismatch distribution. Human Biology 66:591-600

Hartl DL, and Clark AG. 1997. Principles of Population Genetics. Massachusetts: Sinauer Associates.

Herborg L-M, Weetman D, VanOosterhout C, and Hänfling B. 2007. Genetic population structure and contemporary dispersal patterns of a recent European invader, the Chinese mitten crab, Eriocheir sinensis. Molecular Ecology 16:231-242 DOI 10.1111/j.1365294X.2006.03133.x

Ho SW, Phillips M, Cooper A, and Drummond A. 2005. Time dependency of molecular rate estimates and systematic overestimation of recent divergence times. Molecular Biology and Evolution 22:1561-1568 DOI 10.1093/molbev/msil45

Hsü K, Ryan W, and Cita M. 1973. Late Miocene desiccation of the Mediterranean. Nature 242:240-244 DOI 10.1038/242240a0

Irwin DE, Bensch S, and Price TD. 2001. Speciation in a ring. Nature 409:333-337

Jost L. 2008. GST and its relatives do not measure differentiation. Molecular Ecology 17:40154026 DOI 10.1111/j.1365-294X.2008.03887.x

Kass RE, and Raftery AE. 1995. Bayes factors. Journal of the american statistical association 90:773-795 DOI 10.1080/01621459.1995.10476572

Keenan K, McGinnity P, Cross TF, Crozier WW, and Prodöhl PA. 2013. diveRsity: An R package for the estimation and exploration of population genetics parameters and their associated errors. Methods in Ecology and Evolution 4:782-788 DOI 10.1111/2041210X.12067

Kelly RP, Oliver TA, Sivasundar A, and Palumbi SR. 2010. A method for detecting population genetic structure in diverse, high gene-flow species. Journal of Heredity 101:423-436 DOI 10.1093/Jhered/Esq022 
549

550

551

552

553

554

555

556

557

558

559

560

561

562

563

564

565

566

567

568

569

570

571

572

573

574

575

576

577

578

579

580

581

582

583

584

585

586

587

588

589

590

591

592

593

594

Krijgsman W. 2002. The Mediterranean: Mare Nostrum of Earth Sciences. Earth Planet Sci Lett 205:1-12 DOI 10.1016/S0025-3227(98)00084-X

Lemaire C, Versini JJ, and Bonhomme F. 2005. Maintenance of genetic differentiation across a transition zone in the sea: discordance between nuclear and cytoplasmic markers. Journal of Evolutionary Biology 18:70-80 DOI 10.1111/j.1420-9101.2004.00828.x

Mantel N. 1967. The detection of disease clustering and a generalized regression approach. Cancer Reseach 27:209-220

Naranjo C, Sammartino S, García-Lafuente J, Bellanco MJ, and Taupier-Letage I. 2015. Mediterranean waters along and across the Strait of Gibraltar, characterization and zonal modification. Deep-Sea Research Part I Oceanographic Research Papers 105:41-52

Nei M. 1987. Genetic distance and molecular phylogeny. In: Ryman N, and Utter FW, eds. Population Genetics \& Fishery Management. Seattle: Washington Sea Grant Program, University of Washington, 193-223.

Ostellari L, Bargelloni L, Penzo E, Patarnello P, and Patarnello T. 1996. Optimization of singlestrand conformation polymorphism and sequence analysis of the mitochondrial control region in Pagellus bogaraveo (Sparidae, Teleostei): rationalized tools in fish population biology. Animal Genetics 27:423-427 DOI 10.1111/j.1365-2052.1996.tb00510.x

Palumbi S, and Warner R. 2003. Why Gobies Are Like Hobbits? science 299:51 DOI 10.1126/science. 1080775

Paris J, and Quignard J. 1971. La faune ichthyologique des étangs languedociens de Sète a Carnon (Écologie, Éthologie). Vie et Milieu 22:301-327

Patarnello T, Volckaert FAMJ, and Castilho R. 2007. Pillars of Hercules: is the AtlanticMediterranean transition a phylogeographical break? Molecular Ecology 16:4426 — 4444 DOI 10.1111/j.1365-294X.2007.03477.x

Plaut I. 1999. Effects of salinity acclimation on oxygen consumption in the freshwater blenny, Salaria fluviatilis, and the marine peacock blenny, S. pavo. Marine and Freshwater Research 50:655-659

Posada D, and Crandall KA. 1998. Modeltest: testing the model of DNA substituition. Bioinformatics 14:817-818

Posada D, and Crandall KA. 2001. Intraspecific gene genealogies: trees grafting into networks. Trends in Ecology \& Evolution 16:37-45 DOI 10.1016/S0169-5347(00)02026-7

Rambaut A, and Drummond A. 2007. Tracer v1.5. Available from http://beast.bio.ed.ac.uk/Tracer. Available from http://beast.bio.ed.ac.uk/Tracer.

Reece J, Bowen B, Joshi K, Goz V, and Larson A. 2010. Phylogeography of two moray eels indicates high dispersal throughout the Indo-Pacific. Journal of Heredity 101:391-402 DOI 10.1093/jhered/esq036

Reuschel S, Cuesta J, and Schubart C. 2010. Marine biogeographic boundaries and human introduction along the European coast revealed by phylogeography of the prawn Palaemon elegans. Molecular Phylogenetics and Evolution DOI 10.1016/j.ympev.2010.03.021

Robalo JI, Castilho R, Francisco SM, Almada F, Knutsen H, Jorde PE, Pereira AM, and Almada VC. 2012. Northern refugia and recent expansion in the North Sea: the case of the wrasse Symphodus melops (Linnaeus, 1758). Ecology and Evolution 2:153-164 DOI 10.1002/ece 3.77

Ryman N, and Palm S. 2006. POWSIM: a computer program for assessing statistical power when testing for genetic differentiation. Molecular Ecology Notes 6:600-602 
595 Salicru M, Menendez ML, Morales D, and Pardo L. 1993. Asymptotic distribution of (h, $\varphi$ )entropies. Communications in Statistics - Theory and Methods:2015-2031

Verdiell-Cubedo D, Oliva-Paterna F, and Torralva M. 2006. Condition of Salaria pavo in the Mar Menor coastal lagoon (SE Iberian Peninsula): potential influence of environmental variables on juveniles. Journal of Applied Ichthyology 22:407-413

600 Weir BS, and Cockerham CC. 1984. Estimating F-statistics for the analysis of population

601

602 structure. Evolution 38:1358-1370 DOI 10.2307/2408641

Westernhagen Hv. 1983. Observations on the reproductive and larval biology of Blennius pavo 603 (Pisces: Teleostei). Helgoland Marine Research 36:323-335

605

Wright S. 1943. Isolation by distance. Genetics 28:114-138

606

Xavier R, Zenboudji S, Lima FP, HARRIS DJ, Santos AM, and Branco M. 2011. Phylogeography of the marine isopod $q$ (Rezig, 1989) in North African Atlantic and western Mediterranean coasts reveals complex differentiation patterns and a new species. Biological Journal of the Linnean Society 104:419-431 
Figure 1 (on next page)

Schematics of four models.

Figure 1 - Schematics of four models of haplotype frequency distribution and haplotype networks that are expected to result from the scenarios involving panmixia (A), isolation-bydistance (B), secondary contact (C) and phylogeographic barrier (D). 


\section{Hypothesis 1: Panmixia.}

A panmictic population is one in which every individual has

an equal chance of mating with another individual. There is no discernable population structure.

\section{B}

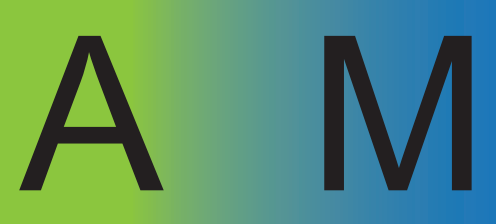

C

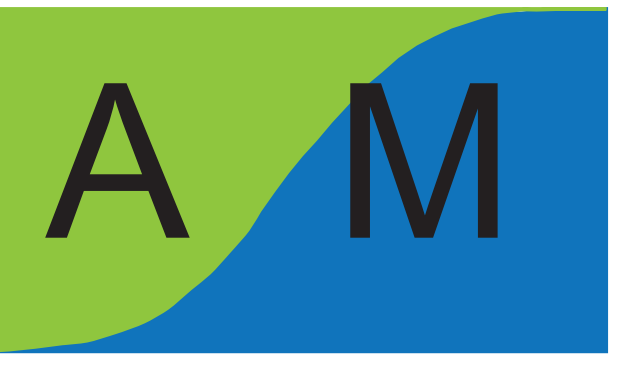

D

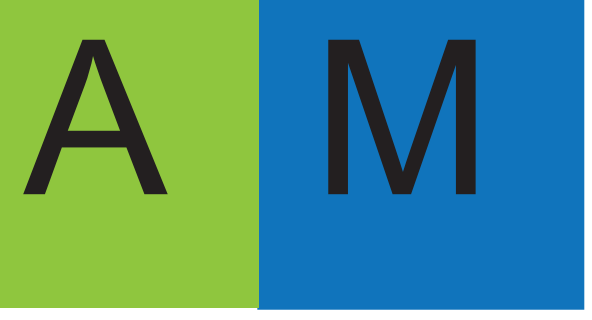

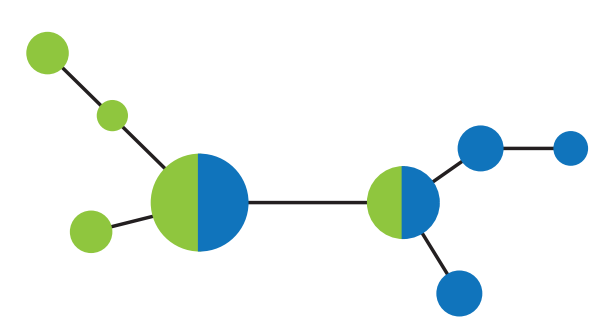
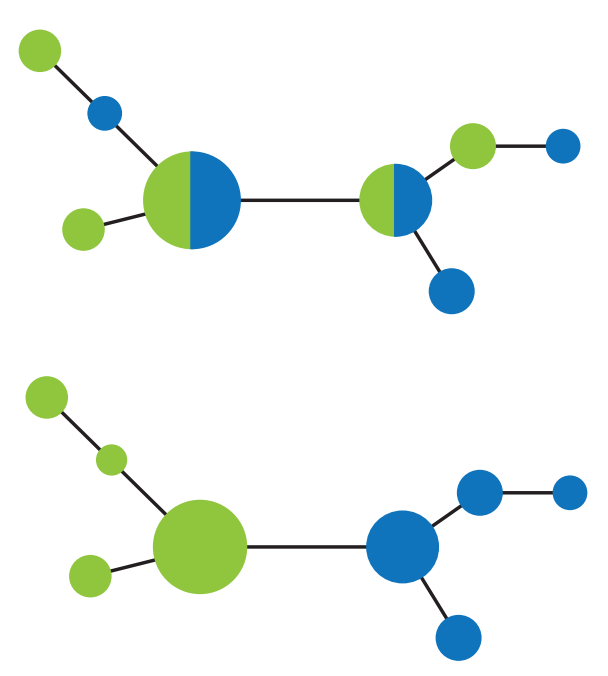

Hypothesis 2: Isolation by distance.

Under models of isolation by distance, many neutral alleles will show cline patterns, especially along geographic axes with the least gene flow.

Hypothesis 3: Secondary contact between populations of the two regions. With secondary contact, neutral alleles will transiently show a cline pattern at the contact zone between the two populations.

The clines along the secondary contact zone will form even if the allele frequency difference between the two populations is modest.

Hypothesis 4: Genetic phylogeographic break between adjacent regions. A sharp geographic boundary between two clades usually assumed to be a result of geographic barriers to dispersal, cryptic species boundaries, or recent contacts between historically allopatric populations. 


\section{Figure 2 (on next page)}

Distribution of D-loop haplotypes of Salaria pavo on each location.

Figure 2 - Distribution of D-loop haplotypes of Salaria pavo on each location. Two-letter codes refer to the name of locations in Table 1. Colours allow comparing the presence of common haplotypes that are present in locations. The biogeographical break of the Almeria-Oran front is represented in red (AOF). 
Figure 3 (on next page)

Median-joining post-processed haplotype network for Salaria pavo .

Figure 3 - Median-joining post-processed control region (A) and S7 (B) haplotype networks for Salaria pavo. The area of the circles is proportional to the frequency of individuals in the sample. Lines are proportional to mutations. Black dots represent median-vectors, or putative haplotypes not sampled or extinct. Colours represent collection location (see key). 


\section{Mediterranean \\ Barcelona \\ Formentera \\ Cabo Gata \\ Atlantic \\ Cadiz \\ Ria Formosa \\ Olhos d'Água \\ Sado \\ Galicia}

\section{A CR}
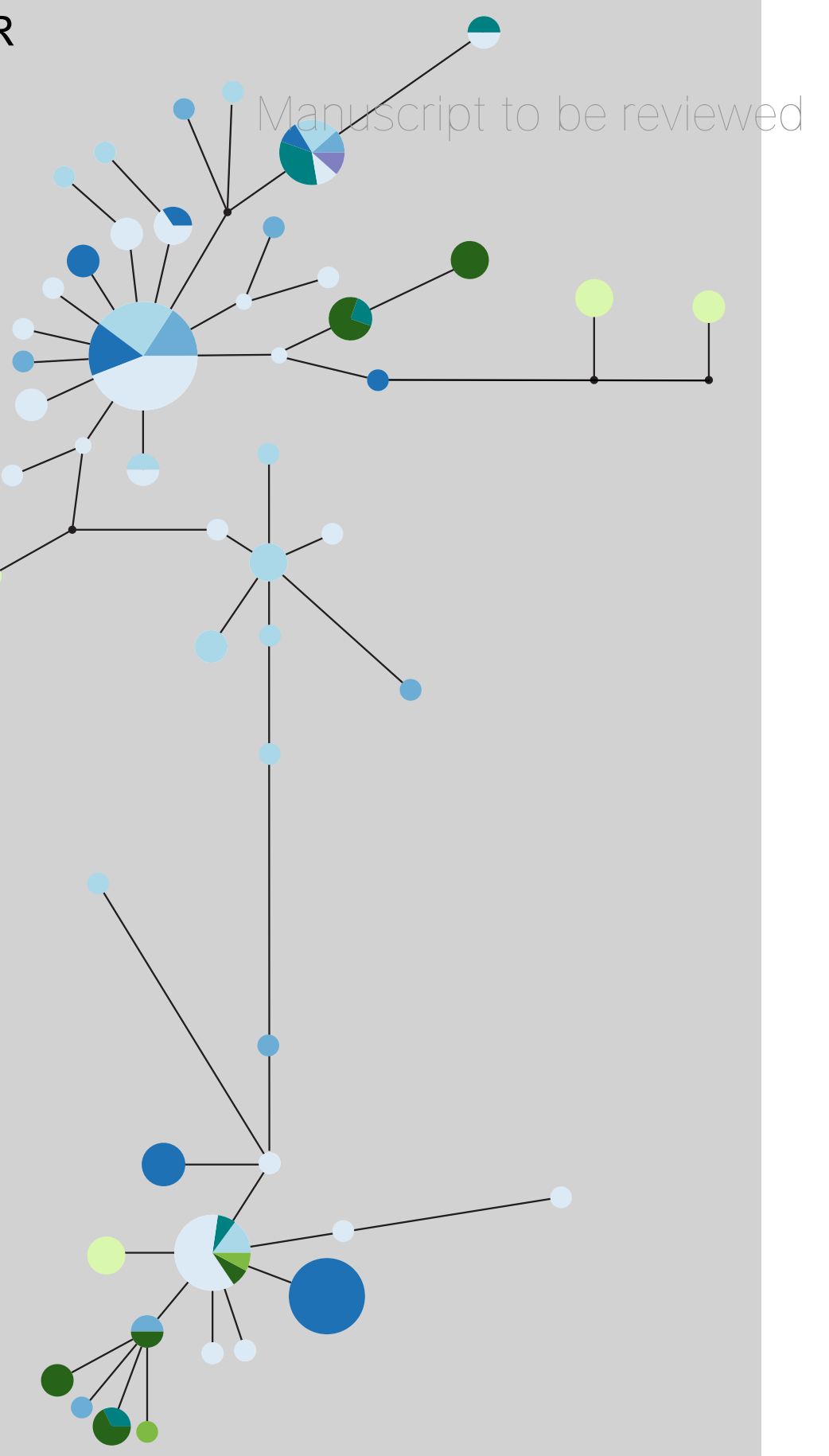

B S7

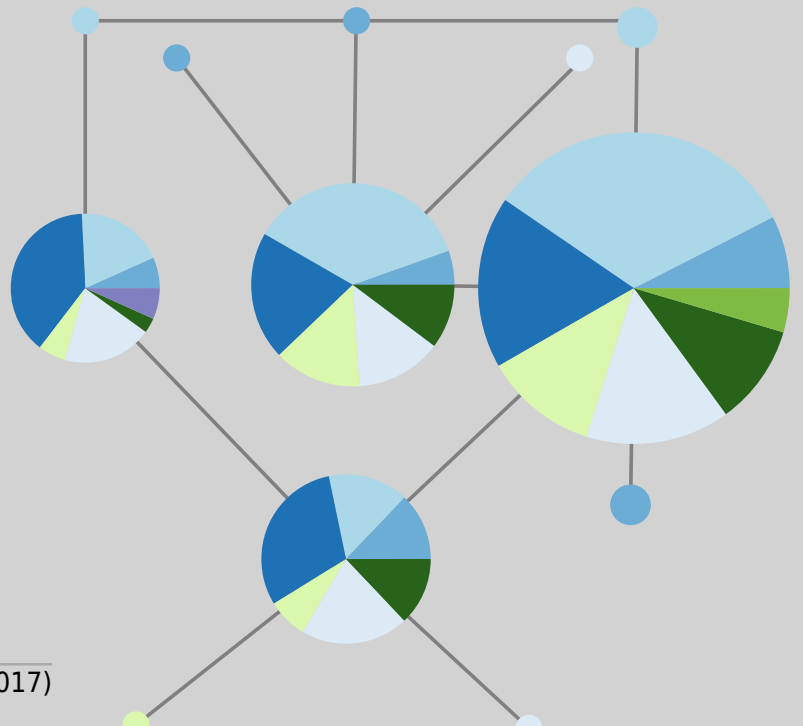


Figure 4 (on next page)

Spatial analysis of shared CR mtDNA distribution of Salaria pavo .

Figure 4 - Spatial analysis of shared alleles for control region (A) and S7 (B). The geographic distances observed between co-occurring alleles and those expected under panmixia are given in in the form of histograms and as cumulative frequency plots. The observed and expected mean distances are indicated with vertical lines. Vertical lines represent the observed and expected mean distances. Triangles and circles are the cumulative frequency of alleles at increasing distance. $p$-value is the probability that the observed mean is greater than the expected. 
Distance Distributions -- Observed Mean: 237 ; Expected Mean: $516 ; p<0.00001$

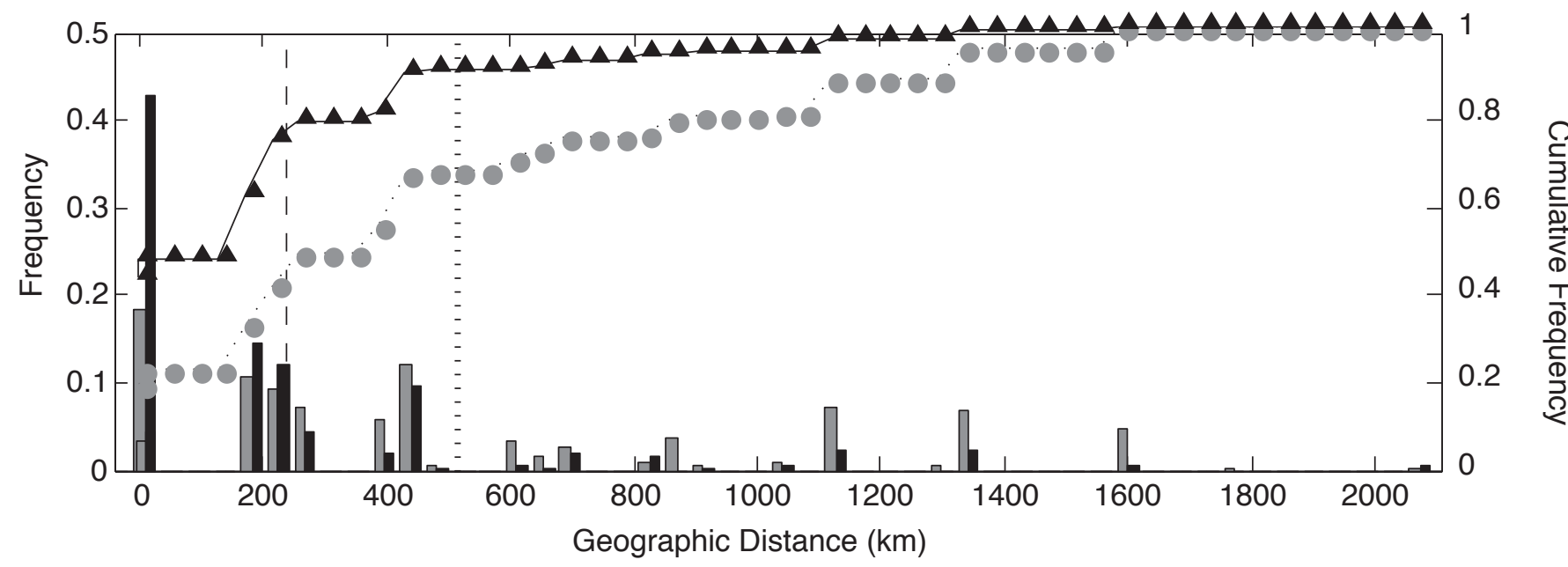

S7

Distance Distributions -- Observed Mean: 521 ; Expected Mean: 508; $p=0.6161$

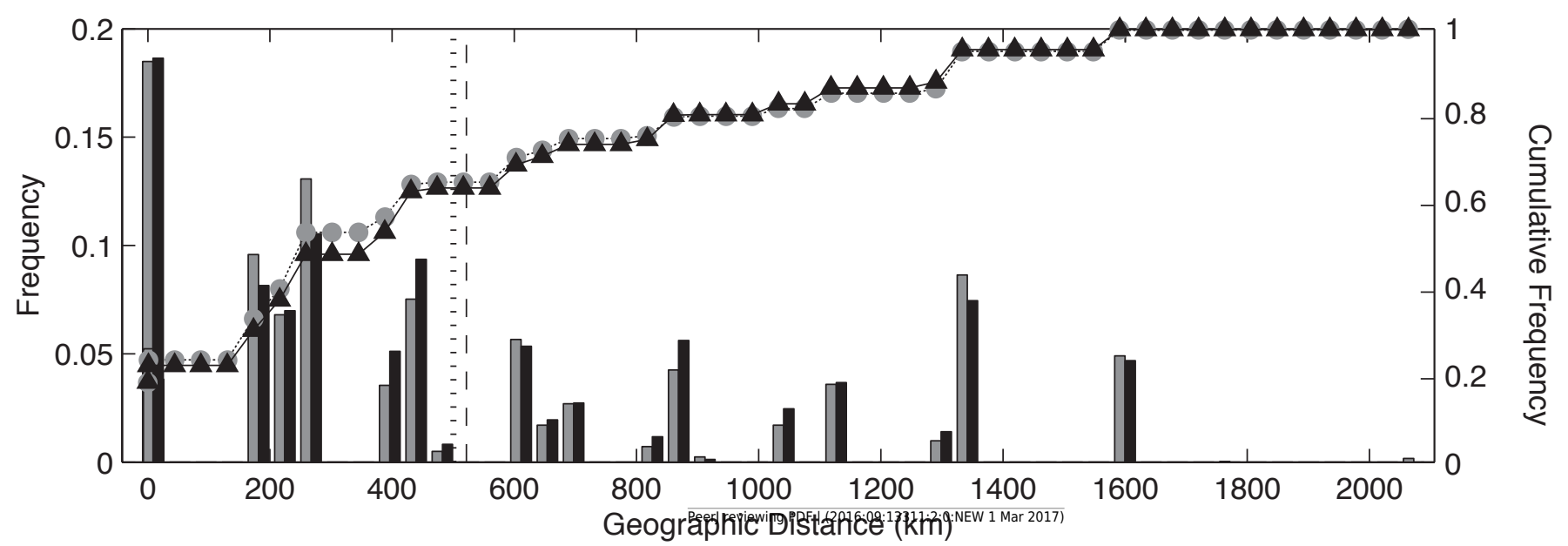

Expected allele frequency

Observed allele frequency

- Expected mean allele frequency

- - Observed mean allele frequency

- Expected cumulative frequence

$\_$Observed cumulative frequence

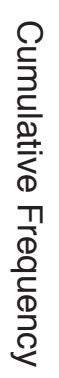


Figure $\mathbf{5}$ (on next page)

$F_{\text {ST, }} \Phi_{\text {ST }}$ and Djost pairwise values

Figure 5 - Mitochondrial differentiation $F_{\mathrm{ST}}, \Phi_{\mathrm{ST}}$ and Djost statistics. A) Average values of the three geographical areas. B) Between location pairs with $N>10$. Location codes as in Fig.2, $\mathrm{BA}=$ Barcelona, $\mathrm{CG}=$ Cabo de Gata, $\mathrm{CA}=\mathrm{Cadiz}, \mathrm{OL}=$ Olhos de Água, $\mathrm{RF}=$ Ria Formosa, $\mathrm{SA}$

$=$ Sado. Significance of differentiation indicated with a circle was assessed through the calculation of $95 \%$ confidence limits using a bias corrected bootstrapping method. Line at 0.0248 indicates $\geq 95 \%$ confidence $(95.5 \%$ Fisher's exact test, $96.2 \%$ chi-square) POWSIM threshold detection of $F_{\text {ST. }}$ 
A
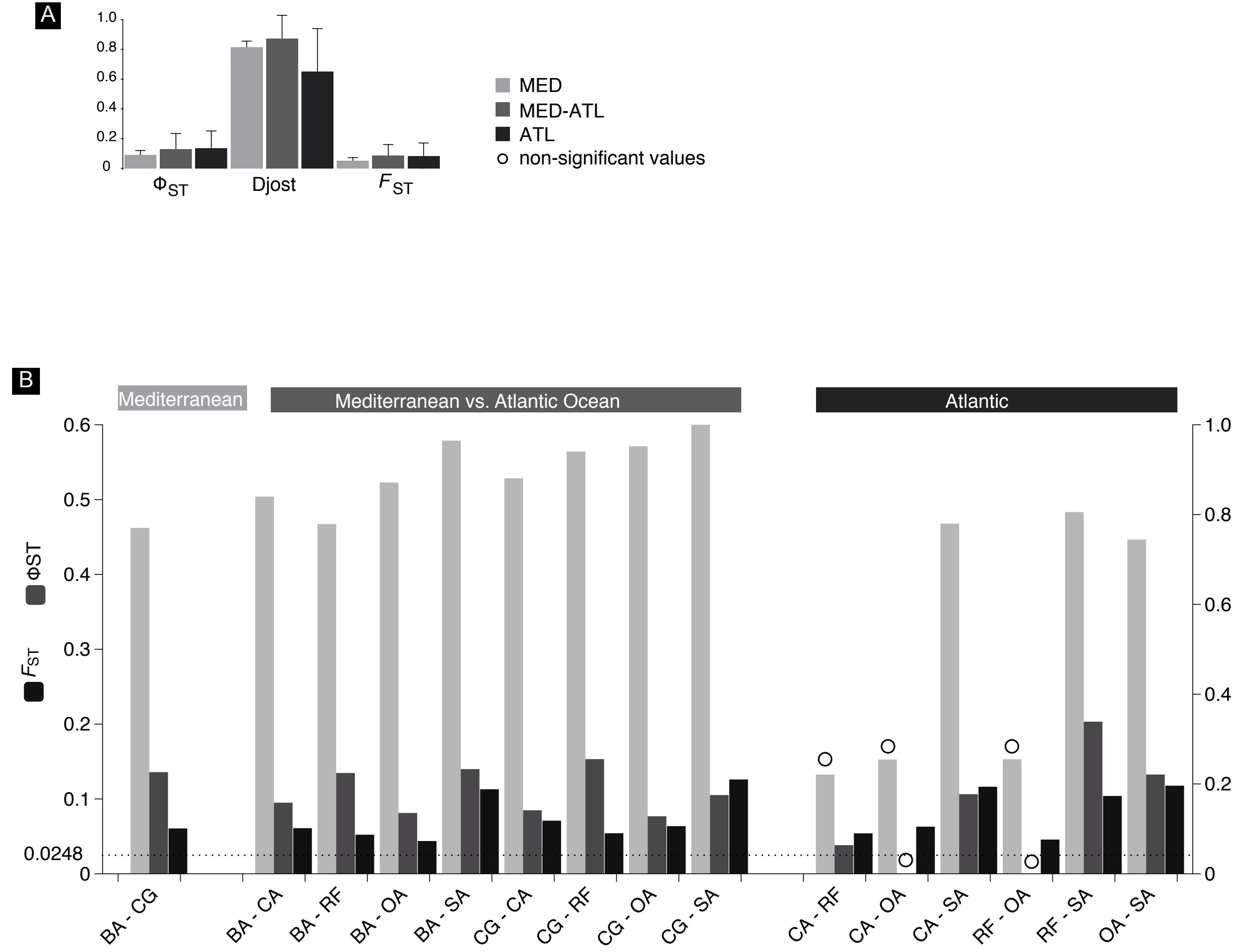
Figure $\mathbf{6}$ (on next page)

Bayesian skyline reconstructions showing the historical demographic trends for Salaria pavo

Figure 6 - Bayesian skyline reconstructions showing the historical demographic trends for Salaria pavo for D-loop sequences. Time, in thousands of years, is shown on the x-axis. Along the $\mathrm{y}$-axis is the expressed population size estimated in units of $\mathrm{Net}$ (Ne: effective population size, $\tau$ : mutation rate per haplotype per generation). The central dark horizontal line in the plot is the median value for effective population size; the light lines are the upper and lower 95\% HPD for those estimates. 


\section{Table $\mathbf{1}$ (on next page)}

Sampling locations of Salaria pavo.

Sample locations, sample abbreviation code, sample sizes and summary statistics for a sequence fragment of the mtDNA D-loop and the first intron of S7 nuclear gene of Salaria pavo. 
1 Table 1 Sample locations, sample abbreviation code, sample sizes and summary statistics for a sequence fragment of the mtDNA D-

2 loop and the first intron of S7 nuclear gene of Salaria pavo.

\begin{tabular}{|c|c|c|c|c|c|c|c|c|c|c|c|c|c|c|c|c|c|c|c|c|c|}
\hline \multirow[b]{2}{*}{ Region } & \multirow[b]{2}{*}{ Locations } & \multirow[b]{2}{*}{ Code } & \multicolumn{10}{|c|}{ Mitochondrial D-loop } & \multicolumn{9}{|c|}{ First intron of S7 gene } \\
\hline & & & $\mathrm{N}$ & NH & NP & $\begin{array}{r}\mathrm{Ha} \\
\text { diver }\end{array}$ & $\begin{array}{l}\text { ploty } \\
\text { ity }\end{array}$ & $\begin{array}{l}\text { pe } \\
\text { s.d. }\end{array}$ & Nucleot & $\begin{array}{l}\text { ide } c \\
\pm \text { s.c }\end{array}$ & iversity & PS & $\mathrm{N}$ & $\mathrm{NH}$ & Gene & $\begin{array}{l}\text { dive } \\
\text { s.d. }\end{array}$ & rsity & Nucleot & $\begin{array}{l}\text { tide } \\
\pm \text { s.c }\end{array}$ & liversity & $\begin{array}{c}\text { Observed } \\
\text { Heterozygosity }\end{array}$ \\
\hline \multirow{3}{*}{ M } & Barcelona & BA & 16 & 9 & 3 & 0.92 & \pm & 0.04 & 0.0520 & \pm & 0.0274 & 38 & 15 & 5 & 0.65 & \pm & 0.07 & 0.0017 & \pm & 0.0013 & 0.53 \\
\hline & Formentera & FO & 2 & 2 & 1 & & & & & & & & 3 & 1 & & & & & & & \\
\hline & Cabogata & $\mathrm{CG}$ & 12 & 6 & 2 & 0.88 & \pm & 0.06 & 0.0167 & \pm & 0.0098 & 10 & 13 & 4 & 0.64 & \pm & 0.07 & 0.0015 & \pm & 0.0013 & 0.46 \\
\hline \multirow{5}{*}{ A } & Cadiz & $\mathrm{CA}$ & 39 & 19 & 13 & 0.88 & \pm & 0.04 & 0.0151 & \pm & 0.0084 & 25 & 22 & 6 & 0.72 & \pm & 0.05 & 0.0019 & \pm & 0.0015 & 0.41 \\
\hline & $\begin{array}{l}\text { Ria } \\
\text { Formosa }\end{array}$ & $\mathrm{RF}$ & 23 & 13 & 8 & 0.94 & \pm & 0.03 & 0.0111 & \pm & 0.0066 & 17 & 40 & 6 & 0.62 & \pm & 0.04 & 0.0016 & \pm & 0.0013 & 0.45 \\
\hline & $\begin{array}{l}\text { Olhos de } \\
\text { Água }\end{array}$ & $\mathrm{OA}$ & 12 & 7 & 6 & 0.91 & \pm & 0.08 & 0.0170 & \pm & 0.0100 & 18 & 12 & 5 & 0.78 & \pm & 0.07 & 0.0023 & \pm & 0.0017 & 0.42 \\
\hline & Sado & SA & 26 & 7 & 4 & 0.72 & \pm & 0.08 & 0.0145 & \pm & 0.0083 & 12 & 30 & 4 & 0.73 & \pm & 0.03 & 0.0019 & \pm & 0.0014 & 0.40 \\
\hline & Galicia & GA & 1 & 1 & 1 & & & & & & & & 1 & 1 & & & & & & & \\
\hline
\end{tabular}

3 N, number of individuals per location; NH, haplotype richness; NP, number of private haplotypes; PS, number of polymorphic sites 


\section{Table 2 (on next page)}

Gene flow amongst Atlantic and Western Mediterranean locations of peacock blenny Salaria pavo.

Gene flow amongst Atlantic and Western Mediterranean locations of peacock blenny Salaria pavo estimated in Migrate-n for mitochondrial DNA data. Differences between each alternative model and model with highest rank are in column dBézier. Exponentiated model differences (column EXP dBézier) are used to estimate model probability dividing EXP dBézier by the sum of all EXP dBézier column values. 
1 Table 2. Comparison of four biogeographic models for Salaria pavo.

\begin{tabular}{cccccc}
\hline \multirow{2}{*}{ Marker } & \multicolumn{2}{c}{ Models } & ML_Bézier & $\begin{array}{c}\text { Log Bayes } \\
\text { factor }\end{array}$ & Probability \\
\hline \multirow{3}{*}{ mtDNA } & Model 1 & Panmixia & -1266.8 & -19.1 & 0.000 \\
& Model 2 & ATL $\leftrightarrow$ MED & -1247.7 & -0.0 & 0.940 \\
& Model 3 & ATL $\rightarrow$ MED & -1250.5 & -2.8 & 0.060 \\
& Model 4 & MED $\rightarrow$ ATL & -1262.0 & -14.3 & 0.000 \\
\hline
\end{tabular}

2

3 